\title{
Engineering Technology Curriculum Development using a Seven Step Back- ward Design Formalism
}

\section{Dr. Soumitra Basu, Fitchburg State University}

Soumitra Basu, Ph.D. is an Assistant Professor in the Department of Industrial Technology at Fitchburg State University, Massachusetts. Dr. Basu has a Ph.D. in Mechanical Engineering from the University of Windsor, Canada, an Master's Degree in Materials Science and Engineering from Penn State, an Master's degree in Production Engineering from Jadavpur University, India, and a Bachelor's degree from BIT Mesra, India. His areas of interest are Green Manufacturing, Industrial Automation and Manufacturing Processes and Systems. Dr. Basu is a member of SME and ASME., and is a past Director of an Engineering Technology Program. 


\section{ENGINEERING TECHNOLOGY CURRICULUM DEVELOPMENTT USING A 7 STEP BACKWARD DESIGN FORMALISM}

\section{ABSTRACT}

Program curriculum development is a critical part of ensuring that universities fulfil their mission. This process can be done in a systematic manner (Taba, 1962). The paper presents a curriculum development model that uses quantitative tools to map the needs of students and industry to the academic programs offered by universities.

The model is based on the 7 step Taba formalism. The first two steps, "Diagnosis of Needs" and "Formulation of Objectives" are discussed in this paper, along with a case study. Quality function deployment enables a model that is responsive to change and provides a highly defined path to identifying and evaluating the program learning objectives.

\section{INTRODUCTION}

The process of developing or updating the curriculum for an academic program can be a long and tedious one. A series of discussion groups generally weigh in on the process, and culminate in a resolution by the administration. This process can be streamlined by using a suitable modeling tool, and creating a method of providing rapid feedback.

Several widely used curriculum development processes follow the model proposed in "Basic Principles of Curriculum and Instruction" (Tyler, 1949). Dr. Hilda Taba, in 1962, added some additional stages and proposed a rigorous curriculum development process that answers the following questions:

1. What are the Needs

2. What are the Objectives

3. What are the Contents

4. How should the contents be organized

5. What should be the learning experience

6. How should the learning experience be organized

7. How should evaluation be carried out

Dr. Hilda Taba was a strong proponent of the backward curriculum development method. This inductive process lends itself to the use of mathematical modeling tools and the application of systems concepts to structure information at various stages of curriculum design.

The sequence of steps proposed by Dr. Taba leads to

- Content Development followed by steps that culminate in

- Outcome Evaluation

The mechanism of going from one step to the other is represented formally in this paper by Quality Function Deployment, or QFD (Akao, 1990), a process where needs are translated in a quantitative manner to a highly defined curriculum structure. 


\section{Objective}

The objective of this paper is to represent the 7 step curriculum development process in the form of a multi-stage input - output model (Leontief, 1966), and employ quality function deployment to map needs to learning objectives (the first 2 steps of the model).

\section{INPUT - OUTPUT SYSTEM FORMALISM}

The entire curriculum development process consists of two parts:

- Content Development

- Outcomes Evaluation

The curriculum development formalism is graphically presented in Figure 1. The starting point is Step 1, where the needs of the curriculum are identified.

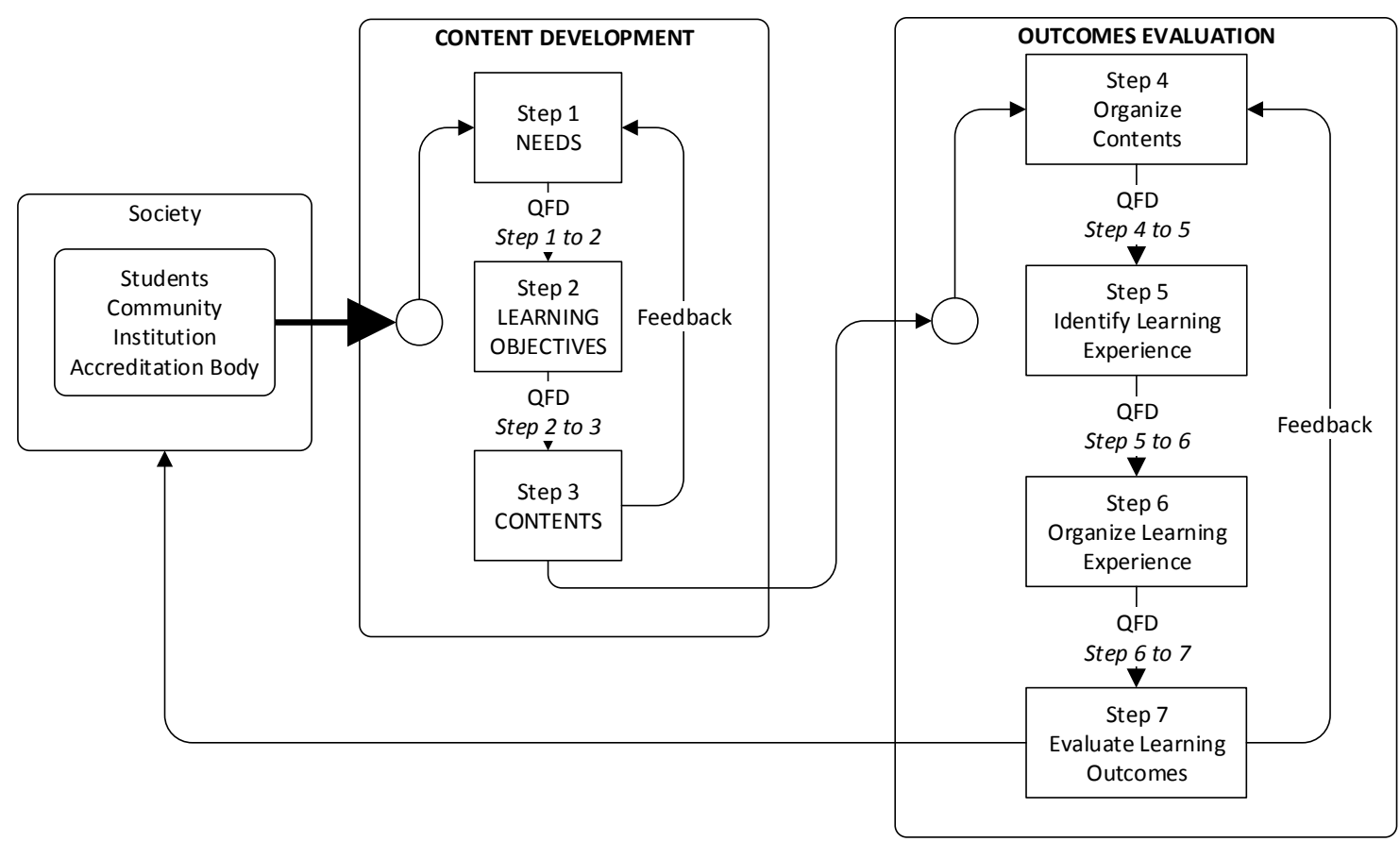

Figure 1: Input / Output System Formalism applied to the 7 step Taba Curriculum Development Model

The overall system model in Figure 1 shows how inputs to the curriculum development system (Steps 1 to 3) are employed to arrive at the contents, and then to the evaluation of learning outcomes (Steps 4 to 7 ).

Clearly, when an entirely new curriculum is created, the content must be developed first, followed 
by the outcomes evaluation processes. Once a curriculum is agreed to, feedback and continuous improvement comes into play. The overall model of the system, including all major interactions, is very large in scope. This paper discusses the needs and the subsequent learning objectives (steps 1 and 2). Quality Function Deployment (QFD) is employed to map the voice of society into the learning objectives.

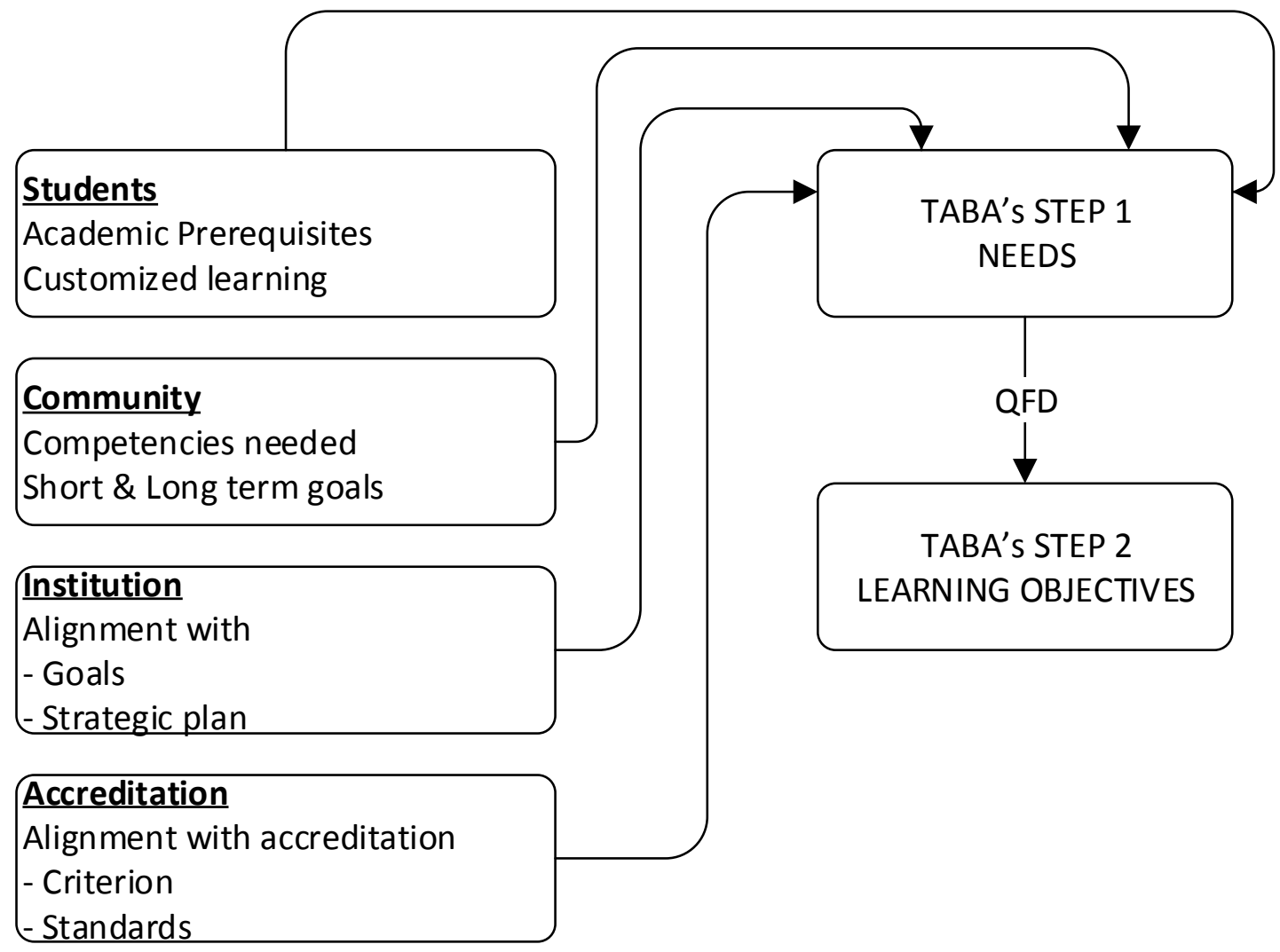

Figure 2: Input / Output System Formalism applied to steps 1 and 2 (the first 2 steps of the content development process).

The needs addressed by the curriculum come from several sources. These are categorized as shown:

\section{Students:}

The curriculum should permit the largest possible fraction of students to enter the program with clearly stated pre-requisite competencies, and have access to contents that match their interests. The contents should have a provision for customization wherever possible. Therefore:

- The curriculum contents need to build on the prerequisite competencies that the program asks of new students. 
- The curriculum contents need to provide pathways of learning that the program professes to provide.

\section{Community:}

Employment opportunities for graduates require competencies. The curriculum contents should provide clearly defined paths for typical students of the program to acquire these competencies. It is important to keep in mind that competency needs change with time, and forward - looking curriculum contents will serve the interests of students better than one that is focused on current competency needs, and certainly better than one that looks exclusively to the past. Thus:

- The curriculum contents need to provide a means for students to acquire the knowledge, skills, ability to use tools and attitudes required for employment by businesses and organizations in the communities of interest

- The curriculum contents need to be "forward looking" as well, since the purpose of the curriculum is to prepare students for the future, while learning from the past

\section{Institution:}

The curriculum contents must be aligned with the goals of the parent institution, and its strategic plan. This requirement has the highest priority. Therefore:

- The program curriculum contents need to support the goals of the parent institution. This is a mandatory need

- The program curriculum contents needs to keep sight of the strategic plan of the parent institution

\section{Accreditation:}

The criterion laid out by accreditation bodies that relate to curriculum contents provides an important mechanism to gauge the quality of an academic program. Both minimum requirements and degree of compliance are important, as a critical input to the continuous improvement process. Thus:

- The program curriculum needs to meet curriculum related criterion mandated by accreditation bodies

- The program contents needs to map a process that will lead to meeting and exceeding the standards mandated by the accreditation body

The next step in the process is to apply the principles of Quality Function Deployment (QFD) to map needs to learning objectives. The Input - Output modeling process is applied to this step: 


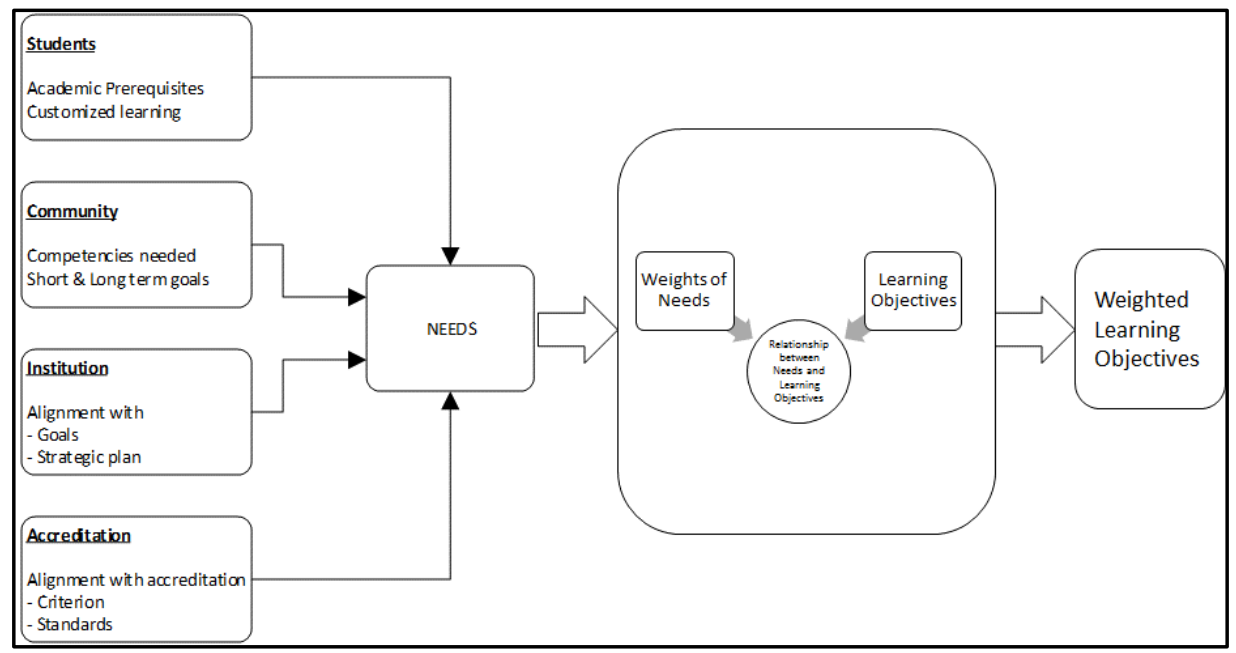

Figure 3 Mapping weighted Needs to weighted Learning Objectives

\section{QUALITY FUNCTION DEPLOYMENT (QFD) MAPPING}

QFD provides a convenient method to determine the relative importance of Learning Objectives. The prerequisite to applying this step, is to come to an agreement regarding appropriate learning outcomes for the program, in consultation with content experts among the faculty. It is important to keep in mind that this is a starting point, and the curriculum contents may lose relevance and rigor in the absence of continuous improvement.

QFD mapping uses the "House of Quality" matrix. The first column contains the Needs. Weights are assigned to the needs based on curriculum committee discussions, led by faculty, with the participation of representatives of the community and professional organizations. This activity could be organized on a periodic basis, with an "advisory committee". Once these are agreed to, the Learning Objectives, agreed to by "content experts" among faculty, are placed in a row as shown. If we consider an example with 3 needs and 3 learning objectives, these variables may be written as the following arrays:

Weights

$$
W=\left\lfloor\begin{array}{l}
W_{1} \\
W_{2} \\
W_{3}
\end{array}\right\rfloor
$$

Learning Objectives

$$
L O=\left[\begin{array}{lll}
L O_{1} & L_{2} & L O_{3}
\end{array}\right]
$$

Relation

$$
R=\left[\begin{array}{lll}
R_{(1,1)} & R_{(1,2)} & R_{(1,3)} \\
R_{(2,1)} & R_{(2,2)} & R_{(2,3)} \\
R_{(3,1)} & R_{(3,2)} & R_{(3,3)}
\end{array}\right]
$$


A "House of Quality" representation of these arrays can be set up and calculated with a variety of computational tools, including spreadsheets. The weights corresponding to each need go on different rows, and the Learning Objectives run along different columns. Relation matrix elements are identified as:

$$
\mathrm{R}_{\text {(column number, row number) }}=\mathrm{R}_{(\mathrm{j}, \mathrm{i})}
$$

Likewise, the computed array, $\mathrm{S}$ can be expressed as

$$
\mathrm{S}_{\text {(column number) }}=\mathrm{S}_{\mathrm{j}}
$$

The index " $\mathrm{i}$ " varies from 1 to $\mathrm{m}$, where $\mathrm{m}=$ the number of learning objectives and the index " $\mathrm{j}$ " varies from 1 to $n$, where $n=$ number of needs.

\begin{tabular}{|c|c|c|c|c|}
\hline & & \multicolumn{3}{|c|}{ Learning Objectives } \\
\hline & & LO $_{1}$ & LO $_{3}$ & $\mathrm{LO}_{3}$ \\
\hline Needs & Weights & & & \\
\hline $\mathrm{N}_{1}$ & $\mathrm{~W}_{1}$ & $\mathrm{R}_{(1,1)}$ & $\mathrm{R}_{(1,2)}$ & $\mathrm{R}_{(1,3)}$ \\
\hline $\mathrm{N}_{2}$ & $\mathrm{~W}_{2}$ & $\mathrm{R}_{(2,1)}$ & $\mathrm{R}_{(2,2)}$ & $\mathrm{R}_{(2,3)}$ \\
\hline $\mathrm{N}_{3}$ & $\mathrm{~W}_{3}$ & $\mathrm{R}_{(3,1)}$ & $\mathrm{R}_{(3,2)}$ & $\mathrm{R}_{(3,3)}$ \\
\hline & & & & \\
\hline & & $\mathrm{S}_{1}$ & $\mathrm{~S}_{2}$ & $\mathrm{~S}_{3}$ \\
\hline
\end{tabular}

Table 1 House of Quality

The sum, $\mathrm{S}_{\mathrm{j}}$ can be written as:

$$
S_{j}=\sum_{\substack{i=1 \\ j=1 \\ j=m}}^{\substack{j=n \\ j=1}} w_{i, j)}
$$

$\mathrm{n}=$ Number of rows

$\mathrm{m}=$ Number of columns

$\mathrm{w}_{\mathrm{j}}=$ Weight of Need $\mathrm{N}_{\mathrm{j}}$

Thus, if $\mathrm{i}=1$, and $\mathrm{j}$ takes values from 1 to 3 ,

$$
S_{1}=\sum\left\{w_{1} \times r_{(1,1)}\right\},\left\{w_{2} \times r_{(2,1)}\right\},\left\{w_{3} \times r_{(3,1)}\right\}
$$

The sum of the weighted relation matrix elements, $S_{1}, S_{2}, .$. provide a metric that shows the impact of needs on learning objectives. 


\section{CaSe Study}

Recently an established Technology program conducted a study to determine the steps needed to seek accreditation as an Engineering Technology program. A detailed selfstudy was conducted, where the curriculum committee asked itself the question: "What are the competencies needed by our students?" It was known that the program graduates sought employment in a number of different areas, and had diverse interests in the broadly defined "Industrial Technology" field. This was reflected in the results of a formal survey done several years earlier, and also by asking students to articulate their preferences.

For illustration purposes, rounded numbers are used in the case study. Also, an abbreviated set of needs related to Community and Institution are shown.

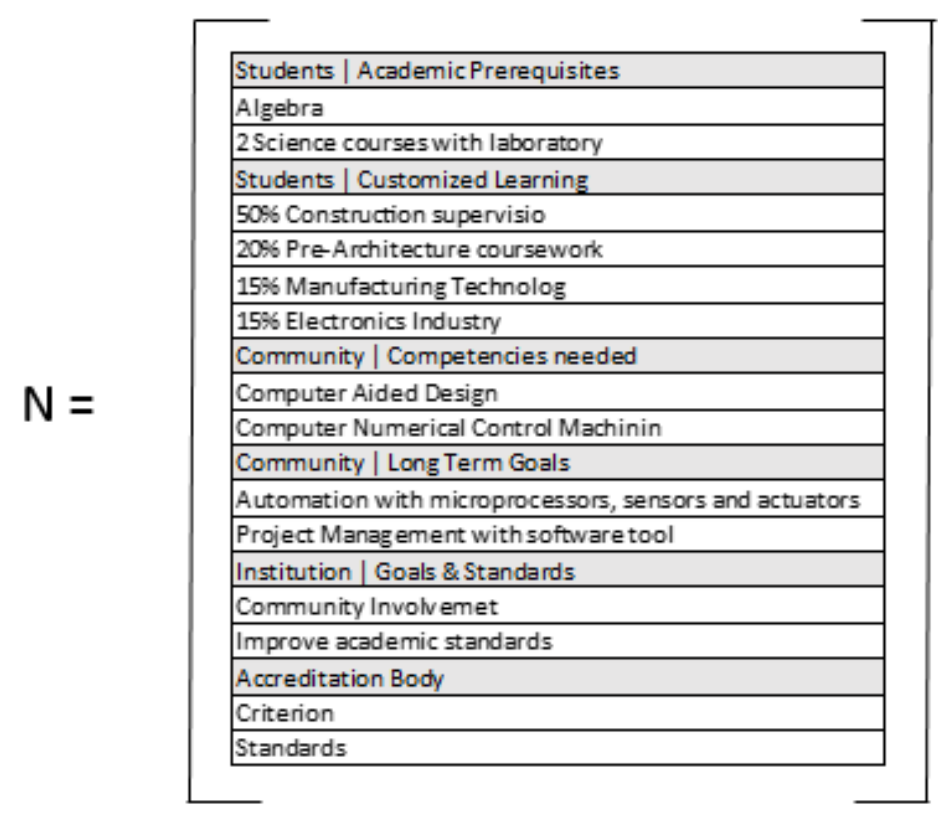

Table 2 Categorized needs

\section{Needs and weights}

Step 1 in the Taba model consists of categorized needs (Table 2) that are examined by the curriculum committee, to create the array of weights. It is important to keep in mind that the array of needs, and the associated weights are a function of the discussions among the curriculum committee and the constituents that are affected by the contents of the curriculum. In this example, these constituents are students, community (organizations that provide employment opportunities to graduates of the program), Institution, and Accreditation agency.

In the course of continuous improvement, feedback from the constituents and the current contents will affect how the curriculum contents change with time.

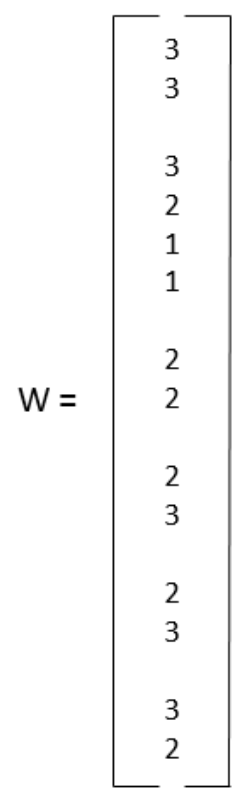

Table 3 Weights 


\section{Learning Objectives}

The curriculum committee consulted content experts in the program to generate a list of learning objectives. These are specific to the program, and the goals of the program as viewed primarily by the faculty, in keeping with the principle of backward design. It is important to keep in mind that the curriculum contents exist for the benefit of the students and society at large, (Note that the program faculty and the institute's administration are considered to be service providers, whose personal interests and bias does not affect the content development process. It is only their expertise that comes into the picture. If this condition is not met, the curriculum development process will cease to benefit students and society at large).

\section{Relationship Array}

The curriculum committee discussed, at length, the relationship of needs and learning objectives. The weights $(1-3)$ reflect the consensual opinions (at the time) of the faculty body, in collaboration with content experts, about the relationship (weak $=1$, moderate $=2$, strong $=3$, no relation $=0$ ) between the weighted needs and the learning objectives.

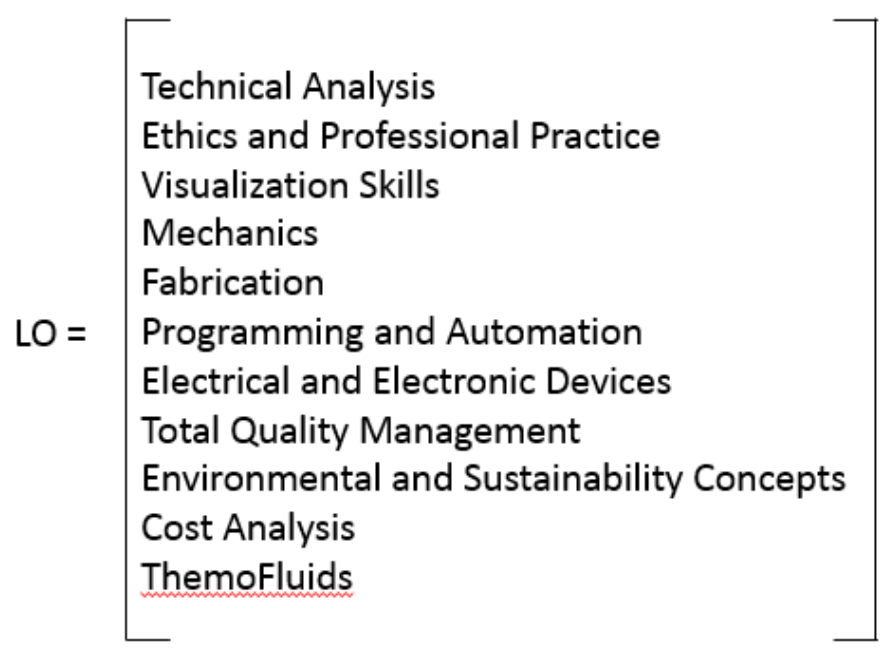

Table 4 Learning Objectives

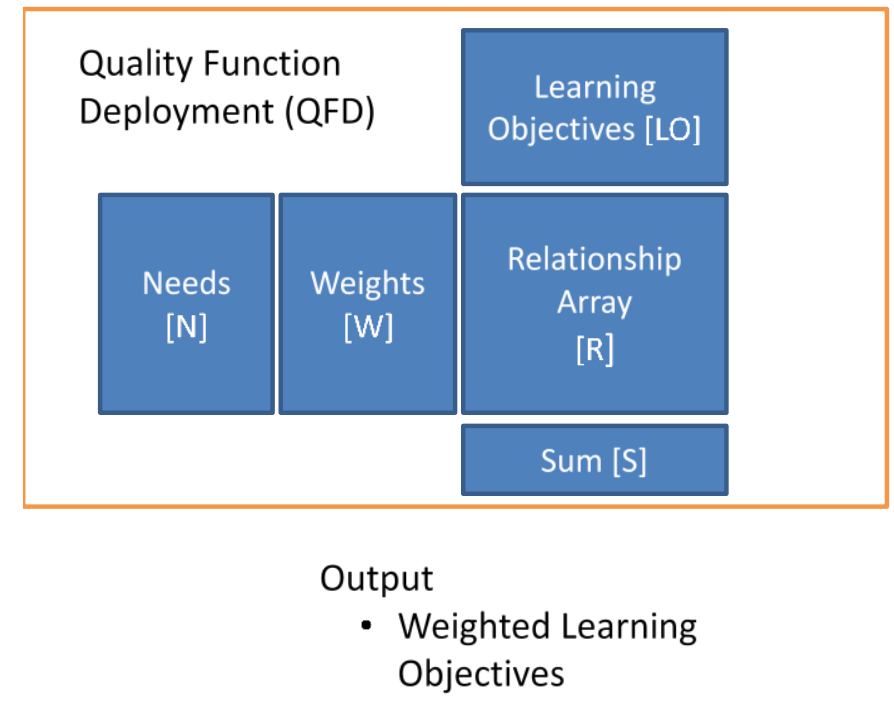

Table 5 Relationship array in the Needs to

Learning Objectives Input - Output Model

- Students

- Community

- Institution

- Accreditation Body

- Feedback 
The House of Quality, incorporating the calculated sum array [S], takes the form depicted in Table 5.

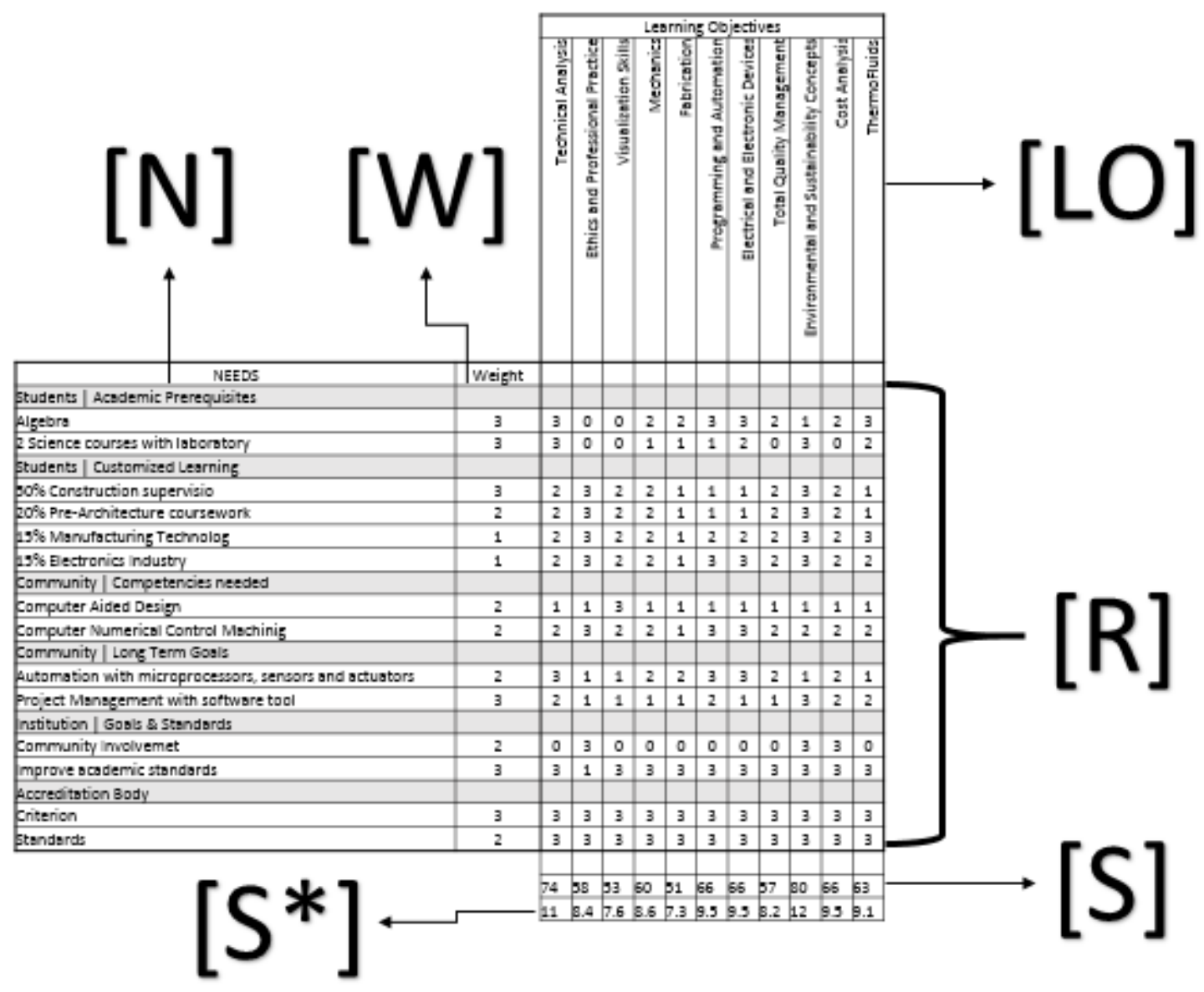

Table 5 Relationship array in the Needs to Learning Objectives Input - Output Model including the computed sum array, $[\mathrm{S}]$

The weighted learning objectives expressed in the form of a percentage, $\left[\mathrm{S}^{*}\right]$, reals that all the learning objectives are important. This is seen in Figure 4 


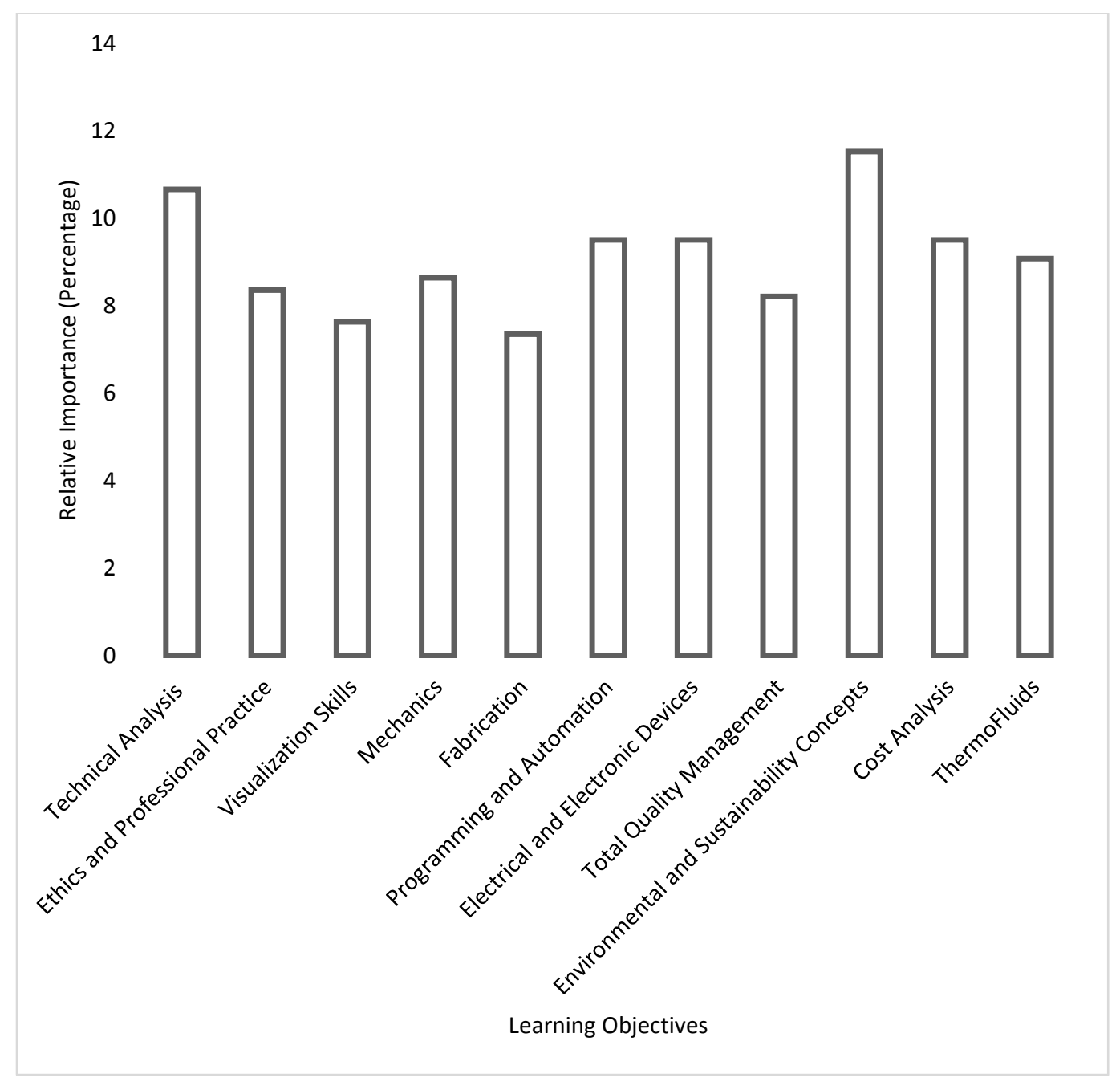

Figure 6 Weighted Learning Objectives [S*]

\section{CONCLUSIONS}

The systems view applied to Dr. Taba's curriculum development model, incorporating concepts of QFD (Quality Function Deployment) provides a formalism (Figure 1) that can be quantitatively modeled. The case study shows how this process is applied to the first 2 steps of the Taba model. This backward curriculum design method, which is conducted by program faculty and content experts, is responsive to the documented needs, and the weights and indices that populate the weights $[\mathrm{W}]$ and $[\mathrm{R}]$ arrays. The computed array $\mathrm{S}^{*}$ and its graphical representation (Figure 6) provides an immediate visual of the relative importance of the learning objectives. 


\section{REFERENCES}

Akao, Y. (1990). Quality Function Deployment: Integrating Customer Requirements into Product Design. New York: Productivity Press .

Leontief, W. (1966). Input-Output Economics. New York: Oxford University Press.

Taba, H. (1962). In H. Taba, Curriculum development: Theory and practice. New York, NY: Harcourt,Brace \& World, Inc.

Tyler, R. W. (1949). Basic Principles of Curriculum and Instruction. Chicago: The University of Chicago Press. 